\section{ENTRE O PASSADO E O FUTURO: UMA DESCRIÇÃO DA PEDAGOGIA CRÍTICA DA EDUCAÇÃO FÍSICA NA LITERATURA ANGLÓFONA}

\author{
BETWEEN PAST AND FUTURE: A DESCRIPTION OF CRITICAL PEDAGOGY OF \\ PHYSICAL EDUCATION IN ANGLOPHONE LITERATURE
}

ENTRE EL PASADO Y EL FUTURO: UNA DESCRIPCIÓN DE LA PEDAGOGÍA DE
LA EDUCACIÓN FÍSICA EN LA LITERATURA ANGLÓFONA

Felipe Quintão Almeida*
Palavras chave: Educação Física. Pedagogia Crítica. Epistemologia.
Resumo: 0 artigo apresenta uma descrição da pedagogia crítica da Educação Física na literatura anglófona. Metodologicamente, baseia-se numa revisão realizada em livros e periódicos que publicam textos a respeito dessa pedagogia em língua inglesa. $A$ análise evidencia as influências teóricas de tal perspectiva, as críticas produzidas pelo discurso sociocrítico (e contra ele) e oferece uma visão sobre seu desenvolvimento nos últimos anos. Expõe, como expressão do pluralismo que o caracteriza, dois exemplos atuais da pedagogia crítica no âmbito da literatura consultada, com ênfase nos desafios futuros dessa tradição.

Keywords:

Physical Education. Critical Pedagogy. Epistemology.

Palabras clave: Educación Física. Pedagogía Crítica. Epistemología.
Abstract: This paper presents a description about critical pedagogy of Physical Education in anglophone literature. Its methodology is based on a review of international books and journals that publish articles on the topic in English language. The analysis shows the theoretical influences of that perspective and the criticism produced by - and against the socio-critical discourse. It also provides an overview about its development in recent years. As an expression of the pluralism that characterizes it, the article also shows two current examples of critical pedagogy in the literature researched, focusing on the future challenges of that tradition.

Resumen: El artículo presenta una descripción de la pedagogía crítica de la Educación Física en la literatura anglófona. Metodológicamente, se basa en una revisión realizada en libros y periódicos que publican textos a respecto de esa pedagogía en lengua inglesa. El análisis muestra las influencias teóricas de esa perspectiva, las críticas producidas por el discurso sociocrítico (y contra él) y ofrece una visión sobre su desarrollo en los últimos años. Expone, como expresión del pluralismo que lo caracteriza, dos ejemplos actuales de la pedagogía crítica en el ámbito de la literatura consultada, con énfasis en los desafíos futuros de esa tradición.
*Universidade Federal do Espírito Santo. Vitória, ES, Brasil. E-mail: fqalmeida@ hotmail.com

Recebido em: 28-03-2019 Aprovado em: 10-06-2019 Publicado em: 30-11-2019

$\mathrm{DOI}$ https://doi.org/10.22456/1982-8918.91416 (c) (i) () Licence 


\section{INTRODUÇÃO}

É notório, no Brasil, o desenvolvimento de uma produção sociocrítica no campo da Educação Física, especialmente aquela que um "movimento renovador" da disciplina tem divulgado a partir dos anos 1980 do século XX. Embora cada vez mais tomemos conhecimento de semelhantes perspectivas em outros países, especialmente os latino-americanos, ainda não são amplamente conhecidas, entre nós, as experiências sociocríticas que publicam seus textos em língua inglesa. ${ }^{1}$ Este texto objetiva, assim, suprir parcialmente essa lacuna ao oferecer uma descrição da pedagogia crítica da Educação Física no contexto da literatura anglófona.

Metodologicamente, realizamos uma investigação em livros considerados importantes e em periódicos que, reconhecidamente, divulgaram, nos últimos anos, a produção sociocrítica em torno da Educação Física na literatura anglófona, como as revistas Quest, Sport, Education and Society, Physical Education and Sport Pedagogy e European Physical Education Review. Este recorte temporal se justifica por ser nesse momento que começam a circular, na literatura consultada, os textos da produção sociocrítica. Consideramos, nesta descrição, apenas os materiais que explicitamente se reportavam a ela, seja no título, seja em seu conteúdo manifesto. Cada edição das revistas foi consultada por meio de suas respectivas páginas eletrônicas. Os textos foram selecionados, inicialmente, pela leitura do título e do resumo. Ao final da catalogação, chegamos a 136 artigos para análise de seu conteúdo. O primeiro deles datado de 1982 e o último de 2019. A análise foi realizada com o objetivo de identificar suas origens, seus objetivos, os pressupostos teóricos, as críticas realizadas e as recebidas, as metodologias mais recorrentes, as transformações em seu discurso ao longo do tempo, bem como as perspectivas a respeito de seu futuro.

O artigo está organizado em três partes. Na primeira, descrevemos as origens, o percurso e algumas críticas direcionadas à pedagogia crítica. Na segunda, antes das considerações finais, destacamos duas versões atuais da pedagogia crítica na literatura consultada.

\section{UM POUCO DE HISTÓRIA: ORIGEM, PERCURSO E CRÍTICAS}

Embora o início das análises sociocríticas na literatura consultada possa ser encontrado já a partir do final dos anos 1970 (BAIN, 1990; DEVÍS-DEVÍS, 2006; KIRK, 1988; ROVEGNO; KIRK, 1995), é possível afirmar que a década seguinte define o surgimento da pedagogia crítica em Educação Física no universo estudado. É partir deste momento que começa a circular uma literatura que se define, ela própria, como crítica. É o que encontramos, por exemplo, no artigo A critical pedagogy for teacher education: toward an inquiry-oriented approach (1986), de David Kirk, ou nos livros Physical Education and curriculum study: a critical introduction (1988), também de David Kirk, e Physical Education, curriculum and culture: critical issues in contemporary crisis (1990), de David Kirk e Richard Tinning.

Esses e outros textos fizeram uma crítica à tradição da disciplina, então marcada pela esportivização, pelo culto da saúde e do corpo perfeito, pelo elitismo motor, pela mecanização/ biologização do corpo em movimento, por práticas estereotipadas e generificantes, pela característica "cientificista/tecnicista" da investigação e por uma didática desprovida de preocupações morais, políticas e sociais. Como alternativa ao currículo "oculto" e às ideologias

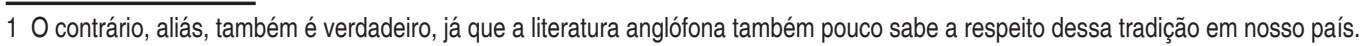


imperantes na Educação Física, conscientização, autorreflexão crítica, emancipação, empoderamento, crítica cultural, inovação curricular, equidade de gênero, mudança e justiça social passaram a ser objetivos declarados no âmbito da pedagogia insurgente. A expectativa era de que a escola e a Educação Física deveriam, no seu interior, desempenhar seu papel na transformação social (KIRK 1986, 1988; TINNING, 1987, 1991). Conforme a interpretação que Macdonald et al. (2002, p. 140) realizaram:

Tipicamente, pesquisadores socialmente críticos fizeram questões sobre as assunções e objetivos de outras pessoas e das suas próprias. Algumas premissas inerentes da crítica social incluíam (a) que alguns grupos na sociedade são poderosos enquanto que outros têm menos poder, (b) poderosos grupos têm interesses particulares na manutenção do poder, (c) o objetivo da investigação é desafiar o status quo e fomentar a transformação social, (d) a reconstrução do social deve ocasionar primeiramente a mudança da consciência individual e dos grupos. $^{2}$

O discurso sociocrítico desenvolveu-se e ecoou em diferentes lugares do universo anglófono, como o Reino Unido, os Estados Unidos, a Austrália ${ }^{3}$ e a Nova-Zelândia, por exemplo. ${ }^{4}$ Entre suas influências iniciais, devemos mencionar as novas direções da sociologia da educação, representadas pelos escritos de Michael Young, e uma sociologia neomarxista ou pós-marxista (Samuel Bowles, Herbert Gintis, Michael Apple, Aronowitz, Henry Giroux, Peter Mclaren, etc.). Não deixa de ser surpreendente, ainda hoje, diga-se de passagem, o reconhecimento da perspectiva educacional de Paulo Freire na produção sociocrítica da Educação Física divulgada em língua inglesa. ${ }^{5}$ Ao mesmo tempo, a metodologia da pesquisaação, representada por nomes como Lawrence Stenhouse, Stephen Kemmis e Wilfred Carr, entre outros, também exerceu sua influência. Intelectuais renomados, como Jurgen Habermas, Pierre Bourdieu e Michel Foucault, também constituíram referências importantes na construção de um discurso crítico da disciplina em sua formulação inicial (DEVÍS-DEVÍS, 2006; KIRK, 1986, 1988, 2000; TINNING, 2010).

Segundo os estudos de revisão dessa tradição conduzidos por Felis-Anaya, MartosGarcia, Devís-Devís (2018) e Devís-Devís (2006, 2012), essa perspectiva não deve ser caracterizada por um conjunto homogêneo de ideias, mas, sim, deve ser lida como uma atividade dinâmica que se autodefine a partir da interação com novos aportes teóricos, característica que, na interpretação deles, dificulta uma rígida diferenciação da investigação crítica de outros paradigmas, como o interpretativo, o feminista e o pós-estruturalista. Nessas circunstâncias, alguns autores vinculados à pedagogia crítica (PHILPOT 2016; ROSSI et al., 2009; TINNING 2010), na esteira de Lather (1998), têm utilizado a expressão "big tenf"6 para se referir ao campo crítico em toda a sua extensão, que é também, muitas vezes, traduzido por expressões como "critical thinking", "critical movement literacy", "socially critical perspective", "critical inquiry", "transformative pedagogy", "radical critical pedagogy", "critical literacy" ou, ainda, "critical health literacy" e "critical movement literacy".

\footnotetext{
2 As traduções, neste artigo, são de minha responsabilidade.

3 Deakin University, na Austrália, é considerada um polo irradiador do discurso crítico no contexto de seu surgimento. A este respeito, consultar Tinning e Sirna (2011) e Devís-Devís (2006, 2012).

4 Embora a Espanha não utilize o inglês como idioma oficial, muito autores espanhóis foram copartícipes desse debate com publicações em língua inglesa. Entre outros, consultar trabalhos de José Devís-Devís e Juan Miguel Fernández-Balboa.

5 Na literatura aqui consultada, sugerimos a leitura de Philpot (2016).

6 Lather (1998) sugeriu ser melhor evitar estabelecer uma definição certa, assumindo a competição entre diferentes compreensões, contranarrativas e vozes contraditórias.
} 
Kirk (2019), em meio a essa pluralidade discursiva, distingue, por um lado, entre 0 que ele chama de "socially critical scholarship", caracterizada como estudos que analisam e criticam a ordem normativa da Educação Física. Para tanto, empregam uma variedade de teorias e métodos para tornar compreensível a complexidade das aulas de Educação Física e programas de formação de professores. Tais investigações buscam "desvelar" interesses injustos e práticas produtoras de desigualdades de diversas ordens. Por outro lado, há o que ele denomina de "critical pedagogy", cuja preocupação é com a organização e o alinhamento do currículo, o ensino, a aprendizagem e avaliações em favor de fornecer uma Educação Física mais inclusiva, justa e equitativa, como uma experiência "incorporada" para pessoas jovens (KIRK, 2019).

Outro aspecto importante da análise de Felis-Anaya, Martos-Garcia e Devís-Devís (2018) e Devís-Devís $(2006,2012)$ é o que eles chamaram de influência dos "postulados pósmodernos" entre os autores preocupados com a construção de uma agenda emancipatória no âmbito da disciplina. Paradigmático, a este respeito, é o livro de Fernández-Balboa (1997), intitulado Critical postmodernism in human movement, physical education and sport. Em seu artigo na coleção, que pode ser traduzido como "Preparação de professores de Educação Física na era pós-moderna: em direção à pedagogia crítica", é exemplar o fato de que não se estabeleceu uma relação de oposição entre o discurso pós e a pedagogia crítica:

Se nós reconhecemos a conectividade entre educação e sociedade, se nós reconhecemos a necessidade de renovar nosso mundo, então nós deveríamos também admitir que uma alternativa pedagógica produzida na direção de criar uma sociedade em que humanos vivem em harmonia e respeitam a natureza é profundamente necessitada - um tipo de pedagogia sintonizada com os tempos pós-modernos. Por meio de tal pedagogia nós podemos nos transformar em cidadãos mais cívicos e politicamente inclinados a lutar por liberdade e justiça. Pedagogia crítica é este tipo de pedagogia. Por isso, em minha opinião, educadores do movimento humano têm a escolha (se não a obrigação moral) de praticar tal pedagogia como uma fonte para o (a) desenvolvimento da consciência pessoal e coletiva, (b) providenciar as necessárias ferramentas emancipatórias, e (c) engajar-se, no plano pessoal e social, em ações transformadoras (FERNÁNDEZBALBOA, 1997, p. 123).

"Desenvolvimento da consciência individual e coletiva", "ferramentas para emancipação" e "engajamento, no plano pessoal e social, em ações transformadoras" são, sem dúvida, princípios iniciais dessa pedagogia, não abandonados com a incredulidade pós-moderna. Esta é, também, a conclusão de Wright (2006, p. 60), para quem, "Em pesquisas na Educação e na Educação Física, investigações pós-modernistas e pós-estruturalistas parecem habitualmente ter um propósito emancipatório". Esta leitura, aliada a outras (MACDONALD; TINNING, 2003; PHILPOT, 2016 TINNING, 2002), exemplifica a alusão positiva à influência "pós" na pedagogia crítica, malgrado o fato de nem todos os pedagogos críticos empregarem a expressão.

Uma das consequências dos postulados "pós" foi a ampliação da paisagem cognitiva da pedagogia crítica, o que culminou com a introdução de conceitos e categorias pouco centrais em suas formulações iniciais (linguagem, discurso, subjetivação, diferença, ética, "embodiment", etc.) e resultou numa crescente diversidade temática. Devís-Devís $(2006,2012)$ e Felis-Anaya, Martos-Garcia e Devís-Devís (2018) evidenciam, retrospectivamente, esse amplo espectro temático, que inclui análises socio-históricas, ideologias, ética do cuidado e responsabilidade,

7 A tradução de "embodiment" poderia ser, também, "personificada", "encarnada". 
cultura física, "embodiment", subjetividades, cultura popular, mulheres, ecologia, etnia, mídia, raça, gênero, habilidade, sexualidade, classe social, imagem corporal, voz dos estudantes, reformas escolares, inovação curricular, neoliberalismo, saúde educacional, formação inicial, carreira e trabalho docente, avaliação educacional, etc.

Metodologicamente, a variedade também é grande e engloba investigações qualitativas a partir da pesquisa-ação, da (auto)etnografia crítica, da história do currículo, da história de vida, da pesquisa colaborativa, dos estudos de caso, das narrativas (auto)biográficas, bem como do desenvolvimento de modelos de ensino que permitiriam práticas mais inclusivas e socialmente orientadas (task-based approach, situated learning, inquiry-oriented approach, student-centredness, inquiry-based learning, activist approach, etc.). A pedagogia crítica foi incorporando ao seu métier essas diferentes perspectivas, temáticas e modos de ensinoaprendizagem.

Essas atualizações e/ou renovações no âmbito do discurso crítico, por sua vez, foram acompanhadas e/ou resultaram de (auto)críticas à produção sociocrítica. Tais (auto)críticas começaram ainda nos anos 1980 e têm origens diversas. Um texto reconhecidamente importante a este respeito foi o de O'Sullivan, Siedentop e Locke (1992). Para eles, a "pedagogia radical da Educação Física", composta por teóricos críticos, feministas e pós-modernistas, poderia ser criticada: pela falta de evidência empírica de suas afirmações; por ser "longa" e utópica em seu criticismo, mas abstrata no oferecimento de alternativas de uma Educação Física diferente; pelo estilo de seu discurso, pejorativo, autoconfiante e repleto de avaliação moral, pressupondo uma

[...] visão de mundo como possuidora de um mais alto nível social e moral de consciência que pode expor mais formas de dominação e provavelmente mais certeza de transformação das práticas culturais consideradas opressivas, injustas ou limitantes. Muitos radicais sugerem que a visão crítica não é apenas outra lente mas apenas a lente em que nós podemos fazer as coisas certas nas atuais lutas/ disputas e debates sobre a direção e conteúdo dos programas de Educação Física (O'SULLIVAN; SIEDENTOP; LOCKE, 1992, p. 272).

Além desses, outros senões foram endereçados à pedagogia crítica. Por exemplo, as dificuldades envolvendo o conceito de "currículo oculto"; o caráter legislador e universalista do discurso crítico; os dilemas da crítica ideológica; os binarismos (bem/mal; crítico/não crítico; progressista/conservador) com os quais operava; os limites da racionalidade (e da reflexividade) no exercício emancipatório, entre outros (BAIN, 1990; GORE, 1990; HICKEY, 2001; MACDONALD, 2002; MACDONALD; BROOKER, 1995; SICILIA-CAMACHO; FERNÁNDEZBALBOA, 2009; TINNING, 2002, 2010). Essas críticas, na avaliação de Felis-Anaya, MartosGarcia e Devís-Devís (2018), levaram os pedagogos críticos a um confronto com crenças mais fundamentais, reconhecendo as dificuldades imanentes ao seu empreendimento. É no âmbito dessa incredulidade que situamos o conceito de "pedagogia modesta" elaborado por Tinning (2002, 2010):

Uma pedagogia modesta não irá assumir que ela tem uma lista de procedimentos pedagógicos que, quando encontrados (descobertos ou inventados), certamente levará a práticas com resultados certos (emancipatório ou conservador). Uma pedagogia modesta irá tomar seriamente a reinvindicação de Bauman (2001) sobre a importância da 'aprendizagem terciária' que informa sobre a capacidade do aprendiz a desaprender e adaptar-se à incerteza (TINNING, 2010, p. 121). 
Como resultado dessas (auto)críticas, reinvenções e/ou redescrições foram sendo produzidas no seio da tradição. Por exemplo, como alternativa ao caráter abstrato e utópico, foram desenvolvidas iniciativas tanto no ensino superior, quanto na escola básica, no sentido de redefinir teorias, métodos e estratégias para tornar a pesquisa crítica prático-referenciada, renovando, assim, a prática (MACDONALD et al., 2002). É o que podemos notar, por exemplo, em inúmeros textos e experiências educativas que procuram materializar, na intervenção, os princípios da pedagogia crítica (FITZPATRICK, 2013; GORE, 1990; KIRK; MACDONALD, 1998; KIRK, 2000; MACDONALD, 2002; OLIVER; KIRK, 2015; PHILPOT, 2016). Apesar de todos os avanços no "plano prático", algumas análises avaliam que ainda há muito por se fazer a esse respeito (FITZPATRICK 2011, 2013; PHILPOT 2016). ${ }^{8}$

Como resposta às insuficiências do ensino reflexivo e da racionalidade para transformar as práticas educativas, pedagogos críticos começaram a defender a importância de se considerar, no âmbito do discurso crítico, o comprometimento emocional de estudantes e professores e, por assim dizer, a "incorporação" e/ou somatização das subjetividades (FITZPATRICK; RUSSEL, 2015; HICKEY, 2001; KIRK, 2018a, 2019; PHILPOT, 2016; TINNING, 2002, 2010;). Segundo concluem, a "Prática reflexiva, contudo, é uma condição necessária, mas não suficiente para melhorar a Educação Física" (MACDONALD; TINNING, 2003, p. 91). Fitzpatrick e Russel (2015, p. 162) afirmaram que, em vez de "cerebral", a pedagogia crítica deveria ser mais "divertida e menos racional". Macdonald e Brooker (1995, p. 102) defenderam que seria central para a pedagogia crítica "[...] cuidado para e cuidado sobre as necessidades dos estudantes". Kirk (1992, p. 10) ${ }^{9}$ argumentou em favor da "sensibilidade emocional, negociação e compromissos", imperativos, para ele (KIRK, 2018a, 2018b, 2018c) $)^{10}$, atualizados pela necessidade de a pedagogia crítica associar-se ao desenvolvimento de "'pedagogias do afeto, ${ }^{11}$ que assumem a aprendizagem afetiva como como uma preocupação central'” (KIRK, 2018b, p. 25).

Essas (auto)críticas, revisões e renovações, resultado da interação com novos aportes teóricos (pluralidade), produziram, após algumas décadas de discursos e práticas, mais de uma "versão" da pedagogia crítica. Exemplificaremos essa pluralidade, no tópico a seguir, a partir da sucinta descrição de dois exemplos. Tomaremos em análise, por um lado, um autor cuja trajetória se confunde com o próprio desenvolvimento da pedagogia crítica na literatura consultada: David Kirk. Possui uma extensa produção dedicada ao tema, tendo desenvolvido essa perspectiva na Austrália, onde foi professor, e no Reino Unido. Atualmente, é professor da University of Strathclyde, na Escócia. Por outro lado, escolhemos avaliar os escritos de Laura Azzarito, professora da Columbia University, em New York (EUA), que também tem se dedicado a desenvolver, mais recentemente, o campo da pedagogia crítica naquele país.

A decisão de tomar dois exemplos bem como a escolha de ambos se baseia nos seguintes critérios: dada a pluralidade de perspectivas críticas num universo tão amplo, consideramos prudente realizar este tipo de "recorte"; são duas "gerações" diferentes, por assim

\footnotetext{
8 Kirk (2019), a partir da distinção que realiza entre "critical pedagogy" e "socially critical scholarship", afirma que, desde a formulação das críticas de O'Sullivan, Siedentop e Locke (1992), dezenas de experiências e modelos de ensino socialmente comprometidos com a transformação social foram produzidos no âmbito da pedagogia crítica. Como resultado, não se dever acusar, hoje, essa perspectiva de ser utópica e abstrata, como fizeram aqueles autores há 27 anos.

9 KIRK, David. Articulations and silences in socially critical research on Physical Education: towards a new agenda. Paper presented at the Australian Associate for Research in Annual Conference, Deakin University, Geelong, Nov. 1992.

10 KIRK, David. Physical Education futures in the Global North. Lecture prepared for the Expomotricidad, Medellin, Colombia, 31 Oct. -2 Nov. 2018c. 
dizer, de pedagogos críticos; atuam em países diferentes e escrevem sobre essa tradição a partir de lugares teóricas distintos; por fim, e a despeito de suas muitas diferenças, atrelam 0 debate sobre o futuro da tradição crítica ao trinômio neoliberalismo/saúde/jovens.

\section{DUAS VERSÕES ATUAIS DA PEDAGOGIA CRÍTICA...}

Para Kirk (2018a, 2018b, 2018c), se o terreno da ação da pedagogia crítica mudou muito desde os anos 1980, e seu próprio trabalho é expressão disso, essa pedagogia deveria transformar-se para enfrentar novos desafios. Um dos estímulos por vir é consequência do fato de a razão de ser da disciplina nos currículos escolares estar transitando do esporte e do lazer para os cuidados com a saúde e o bem-estar. Essa passagem, embora produza perigos, ${ }^{12}$ também abriu, na interpretação de Kirk, possibilidades para a disciplina.

Essa modificação discursiva, por sua vez, não inviabiliza o que, para ele, caracteriza o conhecimento socialmente crítico: a emancipação de práticas produtoras de injustiça social e desigualdade, sejam sexuais, raciais, econômicas, etc.; o empoderamento de indivíduos e grupos e a crítica cultural, entendida como estratégia educacional que permite às pessoas ver além do óbvio, do lugar-comum (KIRK, 2000, 2006). Se o objetivo da pedagogia crítica continua a ser a promoção do conhecimento crítico no reino da cultura física, doravante, "[...] a tarefa é equipar pessoas jovens com a capacidade de fazerem-se informadas para tomarem decisões autônomas sobre sua saúde, bem-estar e "incorporar" as vidas que eles pretendem seguir" (KIRK, 2018c, p. 13). ${ }^{13}$

Ao discutir as possibilidades futuras dessa tarefa, o autor as analisa em tempos caracterizados, a partir de Pierre Bourdieu e Guy Standing, como "turbulentos", produtores de precariedade generalizada (KIRK, 2018a, 2018b, 2018c, 2019). Em seu argumento, a precariedade é um efeito maligno do neoliberalismo e da globalização econômica e impacta devastadoramente na promoção da saúde, do bem-estar e da oportunidade de vida de crianças e jovens. Conforme sua leitura (KIRK, 2018b, p. 16), "[...] viver em precariedade é com toda certeza algo que não é bom para nossa saúde". Nesse contexto, pobreza, posição socioeconômica, violência, desemprego, em suma, as múltiplas privações que afetam a população jovem são elementos chaves para se compreender o binômio precariedade/saúde. "O que é a precariedade e por que ela é tão importante para o futuro da Educação Física?" (KIRK, 2018c, s/p). "Qual pode ser o objetivo e, de fato, a relevância da Educação Física em tempos turbulentos?" (KIRK, 2018a, p. 16). "Quais são as possibilidades da pedagogia crítica agora, quando gerações de pessoas jovens estão enfrentando ou já vivendo em condições de precariedade? (KIRK, 2018a, p. 2).

Uma pedagogia crítica da Educação Física, preocupada com a justiça e a equidade social, deveria desempenhar o papel de desenvolver, entre os professores e outros trabalhadores educacionais, habilidades para problematizar os efeitos da precariedade em suas vidas e nas vidas dos alunos. Como, então, preparar esses professores para o trabalho com jovens que crescem na precariedade? Que danos a precariedade pode produzir no senso de autorrespeito

12 Por exemplo, tomar a fórmula "exercício é medicina" ou a atividade física moderada como "padrão-ouro" para o ensino da Educação Física (KIRK, 2018a).

13 A preocupação com uma alfabetização crítica da saúde e o papel da Educação Física a este respeito são temas já antigos em seu trabalho (KIRK, 1988). Em outros textos, ele tem advogado que "[...] professores e pesquisadores deveriam dar suporte a pessoas jovens para aprender sobre o valor da vida fisicamente ativa" (OLIVER; KIRK, 2015), sendo a perspectiva "salutogênica de saúde" a referência no desenvolvimento de um "boa vida" saudável (KIRK, 2018d). 
e autoidentidade de alunos e professores? Como a precariedade afeta a saúde, o bem-estar e as chances de vida de professores e alunos? Em circunstâncias de precariedade, estaria a pedagogia crítica em condições de oferecer esperança contra os efeitos deste renovado assalto neoliberal? Sua conclusão é que, "Longe de requerer uma pedagogia modesta, nós necessitamos, em minha visão, de uma pedagogia crítica revigorada e afiada, adequada para seus propósitos em tempos turbulentos" (KIRK, 2018a, p. 11-12).

Voltemos nossa atenção, doravante, à perspectiva crítica de Laura Azzarito. Em seus escritos, ela esclarece que seu trabalho é resultado da influência de orientações diversas (embora convergentes), como o pós-feminismo, a teoria crítica da raça, o pós-estruturalismo, os estudos culturais e pós-coloniais (AZZARITO, 2009a, 2010, 2016). Como seu colega Kirk, a autora está preocupada com os impactos produzidos pelo neoliberalismo em questões afetas à Educação Física (corpo, saúde, esporte, etc.), em especial por suas consequências sobre as mulheres e grupos étnicos minoritários, referências que se destacam em seus textos. Azzarito, Simon e Marttinen (2017, p. 206) argumentam que "[...] escolares no campo da Educação Física necessitam repensar e recolocar a agenda da justiça social na direção das atuais inequidades produzidas pela globalização, cuja característica é homogeneizar pessoas jovens na incorporação de normas monoculturais (AZZARITO, 2009b).

De acordo com o diagnóstico da autora, as escolas, sob a influência do imperativo neoliberal, têm produzido, entre os jovens, uma padronização bioidentitária cuja referência é a cultura branca ("whiteness"). ${ }^{14}$ Seu principal efeito é a produção de corpos generificados e racializados que inviabilizam as diferenças (AZZARITO, 2009b, 2010). As comunidades étnicominoritárias e as mulheres que não aderem às globalizadas "White norms" relacionadas à saúde, ao corpo, ao esporte, etc. são representadas em termos negativos, como em "desvantagem", em situação de "risco" por não serem "saudáveis" e "fif", mas gordas, irresponsáveis, desmotivadas, desviantes, em suma, como "outros" em relação àquilo que é estabelecido como norma no universo "whiteness" (AZZARITO; SIMON; MARTTINEN, 2017).

As escolas (uma pedagogia crítica da Educação Física) deveriam funcionar como instituições de resistência e transformação desses discursos que impõem normas, regulam e naturalizam os corpos, enquanto deveriam criar contextos socioeducativos em que os grupos étnico-minoritários e femininos pudessem afirmar sua identidade "[...] por sua própria voz, autorrepresentação e construção do senso de suas experiências de incorporação por meios que consideram relevantes" (AZZARITO, 2016, p. 145). Como o currículo poderia ser redescrito "[...] para empoderar meninas e garotos de diferente etnicidades e classes sociais para expressar suas capacidades corporais livre e completamente, e aprender sobre as regras fundamentais da atividade física em suas vidas? (AZZARITO; SOLOMON, 2005, p. 40). Nessas circunstâncias, uma pedagogia crítica precisaria considerar os distintos modos que "[...] diversas populações constroem, veem e valorizam seus corpos" (AZZARITO; SIMON; MARTTINEN, 2017, p. 211). Para tanto, Azzarito, Simon e Martinen (2017) propõem que a agenda da justiça social desloque seu foco da equidade para a diferença:

O foco na diferença, contudo, representa um novo quadro de requerimentos para se repensar a atual agenda da justiça social com o objetivo de sobreviver aos difíceis desafios dispostos pelo neoliberalismo global. Trabalhos críticos

14 "Whiteness" corresponde a um sistema político, econômico e cultural em que uma raça, a branca, inexoravelmente, controla o poder e detém os recursos materiais. Este sistema assume como norma um discurso específico a respeito dos corpos, em detrimento de "outros" (AZZARITO; SIMON; MARTTINEN, 2017). 
contemporâneos em educação enfatizam a importância de três tipos de esforços: permitir a diferença emergir, estabelecer a experiência como contraditória e reconhecer a identidade como plural. Nós sugerimos que a adoção de abordagens plurais críticas para teorizar a diferença deve aumentar a consciência do múltiplo e conectar as opressões para desmantelar e subverter discursos dominantes sobre o corpo, atividade física, saúde e, portanto, melhorar as pesquisas sobre as atuais inequidades em Saúde e Educação Física. [...] Um objetivo central da abordagem pós-feminista e teoria crítica da raça é desmontar dicotomias de gênero/sexo, classe social, deficiência e raça através do reconhecimento da diferença e da diversidade, bem como a múltipla inter-relação entre diferentes categorias sociais. Construindo-se desde essas posições críticas, o objetivo primário da agenda atual da justiça social é desestabilizar as categorias da identidade, ao mesmo tempo em que deve trabalhar na direção de incrementar a visibilidade dos múltiplos modos em que a etnicidade das pessoas jovens se manifesta subjetivamente, inscrevendo a diferença e desnaturalizando as heteronormativas compreensões classistas e racializadas de corpos saudáveis (AZZARITO; SIMON; MARTTINEN, 2017, p. 211-212).

\section{CONSIDERAÇÕES FINAIS}

O objetivo deste artigo foi oferecer uma descrição (possível) do percurso da pedagogia crítica no âmbito da literatura anglófona da Educação Física. Tarefa decerto difícil, pois essa literatura engloba o desenvolvimento dessa perspectiva em países muito distintos, que têm em comum a língua inglesa ou, então, sua publicação científica nessa língua.

0 exercício foi realizado de modo a descrever, num primeiro momento, o percurso dessa tradição a partir de seu surgimento, enfatizando as principais influências teóricas e suas reivindicações em relação à tradição da disciplina. A análise realizada permitiu concluir que a agenda dessa tradição, desde seu início, incluiu alusões a dimensões além da econômica, absorvendo preocupações atinentes a feminismo, gênero, elitismo motor, racismo, currículo oculto, justiça social, etc. Além disso, a descrição oferecida evidenciou o caráter plural da produção sociocrítica, sendo difícil definir, com precisão, a que tipo de teoria corresponde uma pedagogia crítica no universo estudado. São múltiplas as influências, do pós-modernismo ao pós-estruturalismo, o que ajuda a entender por que alguns autores do campo crítico adotaram a metáfora da "big tent" para se referir a ele em toda a sua extensão. Nesse contexto, a análise também conferiu centralidade ao impacto causado pela "incredulidade pós-moderna" no campo crítico, cujas desconfianças não resultaram num discurso que inviabilizaria a pedagogia crítica ou a possibilidade da emancipação, ${ }^{15}$ mas foram responsáveis por produzir inovações em seu discurso.

Num segundo momento, o artigo ofereceu dois exemplos para expressar a pluralidade de projetos críticos da disciplina na literatura consultada. Escolheu, para tanto, dois autores cujas enunciações partem de lugares distintos. Um deles, David Kirk, que em seus textos não tem a preocupação de afirmar o pertencimento a esta ou àquela tradição teórica; a outra, Laura Azzarito, cujo trabalho é expressão declarada da influência "pós-moderna" e/ou, por assim dizer, de uma filosofia da diferença. As reflexões de ambos permitem conhecer seus argumentos em favor do futuro dessa tradição e de sua agenda emancipatória. Destaque,

15 Embora não nos pareça uma tendência na literatura consultada, Bruce $(2013,2015)$ trabalha com a ideia de uma pedagogia pós-crítica para se referir às mudanças provocadas pela "dúvida pós" no âmbito da perspectiva sociocrítica. 
a este respeito, merece a preocupação da pedagogia crítica com a juventude e a saúde, ${ }^{16}$ duas referências importantes entre os possíveis desafios, conforme os autores resenhados, da pedagogia crítica. Suas análises também evidenciam o que parece ser uma preocupação crescente no âmbito da literatura acessada, quer dizer, os impactos do neoliberalismo e/ou da globalização econômica na Educação Física, particularmente em relação à saúde. ${ }^{17}$

Da mesma forma que Kirk e Azzarito, outros autores, como Richard Tinning, Doune Macdonald, Rod Philpot, John Evans, Sara Flory, Andrew Sparkes, José Devís-Devís, Katie Fitzpatrick, Juan Miguel Fernández-Balboa etc., poderiam ser considerados em nossas análises, o que, certamente, evidenciaria particularidades e diferenças em relação ao futuro dessa tradição crítica. Além deles, poderíamos considerar autores que, apesar de não serem normalmente identificados com a pedagogia crítica, desenvolvem trabalhos ou experiências de ensino em favor da justiça social, como os norte-americanos Kimberly Oliver e Donald (Don) Hellison (KIRK, 2019).

Uma vez familiarizados com a tradição crítica da Educação Física na literatura anglófona, coloca-se a possibilidade de traçar comparações com nossa própria pedagogia crítica, identificando afinidades, diferenças e peculiaridades, num processo que deveria ser de mútuo reconhecimento e aprendizagem. Esta seria a oportunidade para cotejar as referências teóricas mobilizadas quando do seu surgimento com a crítica inicialmente produzida, o modo de apropriação da "dúvida pós-moderna", as críticas endereçadas à pedagogia crítica, as revisões/renovações realizadas em seu seio, bem como, claro, aos futuros vaticinados em relação à sua atualidade. Este é, todavia, um exercício que realizei em outro artigo.

\section{REFERÊNCIAS}

AZZARITO, Laura. Future girls, transcendent femininities and new pedagogies: toward girls' hybrid bodies? Sport, Education and Society, v. 15, n. 3, p. 261-275, 2010.

AZZARITO, Laura. "Permission to Speak": A postcolonial view on racialized bodies and PE in the current context of globalization. Research Quarterly for Exercise and Sport, v. 87, n. 2, p. 141150, 2016.

AZZARITO, Laura. The Panopticon of Physical Education: pretty, active and ideally white. Physical Education and Sport Pedagogy, v. 14, n. 1, p. 19-39, 2009 a.

AZZARITO, Laura. The rise of the corporate curriculum. Fatness, fitness, and whiteness. In: WRIGHT, Jan; HARWOOD, Valerie. Biopolitics and the 'obesity epidemic": Governing bodies. London: Routledge, 2009b. p. 183-196.

AZZARITO, Laura et al. Revitalizing the Physical Education social-justice agenda in the global era: where do we go from here? Quest, n. 69, v. 2, p. 205-219, 2017.

AZZARITO, Laura; SIMON, Mara; MARTTINEN, Risto. 'Up against whiteness': rethinking race and the body in a global era. Sport, Education and Society, v. 22, n. 5, p. 635-657, 2017.

16 A relação entre Educação Física e saúde é tema recorrente entre os pedagogos críticos na literatura consultada.

17 A este respeito, sugiro consultar, entre outros, Evans (2014), Evans e Davies (2015), Macdonald (2014) e Fernández-Balboa (2017). 
AZZARITO, Laura; SOLOMON, Melinda. A reconceptualization of Physical Education: the intersection of gender/race/social class. Sport, Education and Society, v. 10, n. 1, p. 25-47, 2005.

BAIN, Linda. A critical analysis of the hidden curriculum. In: KIRK, David; TINNING, R. Physical education, curriculum and culture: critical issues in the contemporary crisis. London: Falmer, 1990. p. 23-42.

BRUCE, Judy. Dancing on the edge: a self-study exploring postcritical possibilities in Physical Education. Sport, Education and Society, v.18, n. 6, p. 807-824, 2013.

BRUCE, Judy. On racism and prejudice: exploring post-critical possibilities for service-learning within Physical Education teacher education. Asia-Pacific Journal of Health, Sport and Physical Education, v. 6, n. 3, p. 233-244, 2015.

DEVÍS-DEVÍS, José. La investigación sociocrítica en la Educación Física. Estudios Pedagógicos, v. 38, número especial, p. 125-153, 2012.

DEVÍS-DEVÍS, José. Socially critical research perspectives in Physical Education. In: KIRK, David; MACDONALD, Doune; O'SULLIVAN, Mary. The Handbook of Physical Education London: SAGE, 2006. p. 37-85.

EVANS, John. Neoliberalism and the future for a socio-educative Physical Education. Physical Education and Sport Pedagogy, v. 19, n. 5, p. 545-558, 2014.

EVANS, John; DAVIES, Brian. Neoliberal freedoms, privatisation and the future of Physical Education. Sport, Education and Society, v. 20, n. 1, p. 10-26, 2015.

FELIS-ANAYA, Mercè, MARTOS-GARCIA, Daniel; DEVIIS-DEVÍS, José. Socio-critical research on teaching Physical Education and Physical Education teacher education: a systematic review. European Physical Education Review, v. 24, n. 3, p. 314-329, 2018.

FERNÁNDEZ-BALBOA, Juan Miguel. A contrasting analysis of the neoliberal and socio-critical structural strategies in health and: reflections on the emancipatory agenda within and beyond the limits of HPE. Sport, Education and Society, v. 22, n. 5, p. 658-668, 2017.

FERNÁNDEZ-BALBOA, Juan Miguel. Physical Education teacher preparation in the postmodern era: toward a critical pedagogy. In: FERNÁNDEZ-BALBOA, Juan Miguel. Critical postmodernism in human movement, Physical Education and sport. Albany: Sunny, 1997. p. 121-138.

FITZPATRICK, Katie. Critical pedagogy, Physical Education and urban schooling. New York: Peter Lang, 2013.

FITZPATRICK, Katie. Obesity, health and Physical Education: a bourdieuean perspective. Policy futures in education, v. 9, n. 3, p. 353-366, 2011.

FITZPATRICK, Katie; RUSSELL, Dan. On being critical in health and Physical Education. Physical Education and Sport Pedagogy, v. 20, n. 2, p. 159-173, 2015.

GORE, Jennifer. Pedagogy as text in Physical Education teacher education: beyond the preferred reading. In: KIRK, David; TINNING, Richard. Physical Education, curriculum and culture: critical issues in the contemporary crisis. London: Falmer, 1990. p. 101-138.

HICKEY, Christopher. "I feel enlightened now, but...": the limits of the pedagogical translation of critical social discourses in Physical Education. Journal of Teaching in Physical Education, v. 20, n. 3, p. 227-246, 2001. 
KIRK, David. A critical pedagogy for teacher education: towards an inquiry-oriented approach. Journal of Teaching in Physical Education, v. 5, n. 4, p. 230-246, 1986.

KIRK, David. Physical Education and curriculum: a critical introduction. London/New York: Routledge, 1988.

KIRK, David. A task-based approach to critical pedagogy in sport and Physical Education. In: JONES, Robyn; HARLOW, Katheelen. Sociology of sport: theory and practice. Pearson, 2000. p. 201-219.

KIRK, David. Sport education, critical pedagogy, and learning theory: toward an intrinsic justification for Physical Education and youth sport. Quest, v. 58, n. 2, p. 255-264, 2006.

KIRK, David. A new critical pedagogy for Physical Education in turbulent times: what are the possibilities? In: PRINGLE, Richard; LARSSON, Lena; GERDIN, Göran. Critical research in sport, health and Physical Education: how to make a difference. Milton Park, Abingdon: Oxon, 2018a. p. 1-25.

KIRK, David. Precarity and physical education. Revista da Associación Latino-Americana de Estudios Socioculturales del Deporte, v. 9, n. 1, p. 15-28, 2018b.

KIRK, David. Physical Education-as-health promotion: recent developments and future issues. Education and Health, v. 36, n. 3, p. 70-75, 2018d.

KIRK, David. Precarity, critical pedagogy and Physical Education. London: Routledge, 2019.

KIRK, David; MACDONALD, Doune. Situated learning in Physical Education. Journal of Teaching in Physical Education, v. 17. n. 3, p. 376-87, 1998.

KIRK, David; TINNING, Richard. Physical Education, curriculum and culture. London: Falmer, 1990.

LATHER, Patti. Critical pedagogy and its complicities: a praxis of stuck places. Educational Theory, v. 48, n. 4, p. 487-497. 1998.

MACDONALD, Doune. Critical pedagogy: what might it look like and why does it matter? In: LAKER, Anthony. The sociology of Sport and Physical Education. London: Routledge, 2002, p. 167-189.

MACDONALD, Doune. Is global neo-liberalism shaping the future of Physical Education? Physical Education and Sport Pedagogy, v. 19, n. 5, p. 494-499, 2014.

MACDONALD, Doune et al. "It's all very well, in theory: theoretical Perspectives and their applications in contemporary pedagogical research." Quest, v. 54, n. 2, p. 133-154, 2002.

MACDONALD, Doune; BROOKER, Ross. Professional education: tensions in subject design and implementation. Educational Research and Perspectives, 22, n. 2, p. 99-109, 1995.

MACDONALD, Doune; TINNING, Richard. Reflective practice goes public: reflection, governmentality and postmodernity. In: LAKER, Anthony. The future of Physical Education: building a new pedagogy. London: Routledge, 2003. p. 82-101.

OLIVER Kimberly; KIRK, David. Girls, gender and Physical Education: an activist approach. Abingdon, UK: Routledge, 2015. 
O'SULLIVAN, Mary; SIEDENTOP, Daryel; LOCKE, Lawrence. Toward collegiality: competing viewpoints among teacher educators. Quest, v. 44, n. 2, p. 266-280, 1992.

PHILPOT, Rod. Kicking at the habitus: exploring staff and student 'readings' of a socially critical physical education teacher education (PETE) programme. 2016. Doctor (Philosophy in Education) - University of Auckland, Auckland, 2016.

ROSSI, Tony et al. With the best of intentions: a critical discourse analysis of Physical Education curriculum materials. Journal of Teaching in Physical Education, v. 28, p. 75-89, 2009.

ROVEGNO, Inez; KIRK, David. Articulations and silences in socially critical work on Physical Education: toward a broader agenda. Quest, v. 47, n. 4, p. 447-474, 1995.

SICILIA-CAMACHO, Alvaro; FERNÁNDEZ-BALBOA, Juan Miguel. Reflecting on the moral bases of critical pedagogy. In: PETE: toward a foucaultian perspective on ethics and the care of the self. Sport, Education and Society, v. 14, n. 4, p. 443-463, 2009.

TINNING, Richard. Improving teaching in Physical Education. Geelong: Deakin University, 1987.

TINNING, Richard. Pedagogy and human movement: theory, practice, research. New York: Routledge. 2010.

TINNING, Richard. Teacher education pedagogy: dominant discourses and the process of problem solving. Journal of Teaching in Physical Education, v. 11, n. 1, p. 1-20, 1991.

TINNING, Richard. Toward a "modest pedagogy": reflections on the problematics of critical pedagogy Quest, v. 54, n. 3, p. 224-240, 2002.

TINNING, Richard; SIRNA, Karen. Education, social justice and the legacy of Deakin University. Rotterdam: Sense, 2011.

WRIGHT, Jan. Postmodern, poststructural and postcolonial research in Physical Education. In: KIRK, David; MACDONALD, Doune; O'SULLIVAN, Mary. The Handbook of Physical Education London: SAGE, 2006. p. 59-75.

\section{Agradecimentos:}

Gostaria de agradecer o apoio e a acolhida do professor David Kirk durante meu estágio de pósdoutorado na Universidade de Strathclyde.

\section{Apoio:}

O presente trabalho foi realizado com apoio da Coordenação de Aperfeiçoamento de Pessoal de Nível Superior - Brasil (CAPES) - Código de Financiamento 001. This study was financed in part by the Coordenação de Aperfeiçoamento de Pessoal de Nível Superior - Brasil (CAPES) Finance Code 001. 